\title{
Significant Improvement of Left Atrial and Left Atrial Appendage Function After Catheter Ablation for Persistent Atrial Fibrillation
}

Tomoko Machino-Ohtsuka, MD; Yoshihiro Seo, MD, PhD; Tomoko Ishizu, MD, PhD;

Satomi Yanaka, BSc; Hideki Nakajima, PhD; Akiko Atsumi, MD; Masayoshi Yamamoto, MD;

Ryo Kawamura, MD; Yuki Koshino, MD, PhD; Takeshi Machino, MD; Kenji Kuroki, MD;

Hiro Yamasaki, MD; Miyako Igarashi, MD, PhD; Yukio Sekiguchi, MD, PhD;

Hiroshi Tada, MD, PhD; Kazutaka Aonuma, MD, PhD

Background: The long-term effects of catheter ablation (CA) on the left atrium and left atrial appendage (LAA) are unknown in persistent atrial fibrillation (AF). This study investigated left atrial (LA) reverse remodeling and evolution of LA/LAA function after successful CA for persistent AF and identified predictors for maintenance of sinus rhythm (SR) and LA reverse remodeling.

Methods and Results: CA was performed in 123 patients with persistent AF. LA volumes, LA strain and LAA wall velocity were assessed both at baseline and at 12 months after ablation. Patients who maintained SR were divided into 2 groups according to whether LA volume decreased by $\geq 15 \%$ at follow-up (responders) or not (non-responders). During a follow-up period of $18 \pm 2$ months, AF recurred in 45 patients (37\%). Of the remaining 78 patients $(63 \%)$ without recurrent AF, 62 patients $(79 \%)$ were classified as responders. LA/LAA function significantly improved and the prevalence of spontaneous echo contrast decreased only in responders at follow-up. LA systolic strain and LAA wall velocity were independent predictors of both maintenance of $\mathrm{SR}$ (odds ratio [OR], 2.57; $\mathrm{P}=0.003 ; \mathrm{OR}, 3.02$; $P=0.002$, respectively) and $L A$ reverse remodeling (OR, 4.44; $P=0.007 ; O R, 3.52 ; P=0.01$, respectively).

Conclusions: Successful CA is associated with LA reverse remodeling and LA/LAA functional recovery in patients with persistent AF. LA systolic strain and LAA wall velocity at baseline predicted both maintenance of SR and LA reverse remodeling. (Circ $J$ 2013; 77: 1695-1704)

Key Words: Atrial fibrillation; Atrial strain; Catheter ablation; Echocardiography

$\mathbf{S}$ ustained and prolonged atrial fibrillation (AF) is often associated with adverse structural and histological changes to the left atrium (LA) and left atrial appendage (LAA).$^{1-4}$ In comparison to patients with paroxysmal AF, patients with persistent AF often have poorer left ventricular ejection fraction (LVEF) and impaired left ventricular (LV) diastolic function. ${ }^{5,6}$ Patients who progress to more persistent forms of AF are admitted to hospital more frequently, with an increased incidence of major adverse events, including stroke and cardiovascular death, when compared to patients with paroxysmal AF. ${ }^{7,8}$ Thus, severe atrial remodeling is associated with cardiac dysfunction and a poorer prognosis; moreover, LAA dysfunction increases risk of thromboembolism. ${ }^{9}$ Therefore, LA reverse remodeling, including LA/LAA functional recovery after catheter ablation $(\mathrm{CA})$ for $\mathrm{AF}$, may be as clini- cally relevant as the maintenance of sinus rhythm (SR). Detailed functional evaluations of the LA/LAA after CA for patients with persistent AF, however, are still lacking. The aim of the present study was to evaluate the effects of successful CA for persistent AF on LA reverse remodeling and recovery of LA/LAA functions during long-term follow-up. Predictors for maintenance of SR and LA reverse remodeling were also studied.

\section{Editorial p1681}

Methods
Subjects and Protocol
Between January 2007 and March 2010, 210 patients with

Received December 7, 2012; revised manuscript received January 15, 2013; accepted February 7, 2013; released online March 26, 2013 Time for primary review: 17 days

Cardiovascular Division, Faculty of Medicine, University of Tsukuba, Tsukuba (T.M.-O., Y. Seo, T.I., A.A., M.Y., R.K., Y.K., T.M., K.K., H.Y., M.I., Y. Sekiguchi, H.T., K.A.); Department of Clinical Laboratory, Tsukuba University Hospital, Tsukuba (S.Y., H.N.), Japan

Mailing address: Kazutaka Aonuma, MD, Cardiovascular Division, Faculty of Medicine, University of Tsukuba, 1-1-1 Tennodai, Tsukuba 305-8575, Japan. E-mail: kaonuma@md.tsukuba.ac.jp

ISSN-1346-9843 doi:10.1253/circj.CJ-12-1518

All rights are reserved to the Japanese Circulation Society. For permissions, please e-mail: cj@j-circ.or.jp 

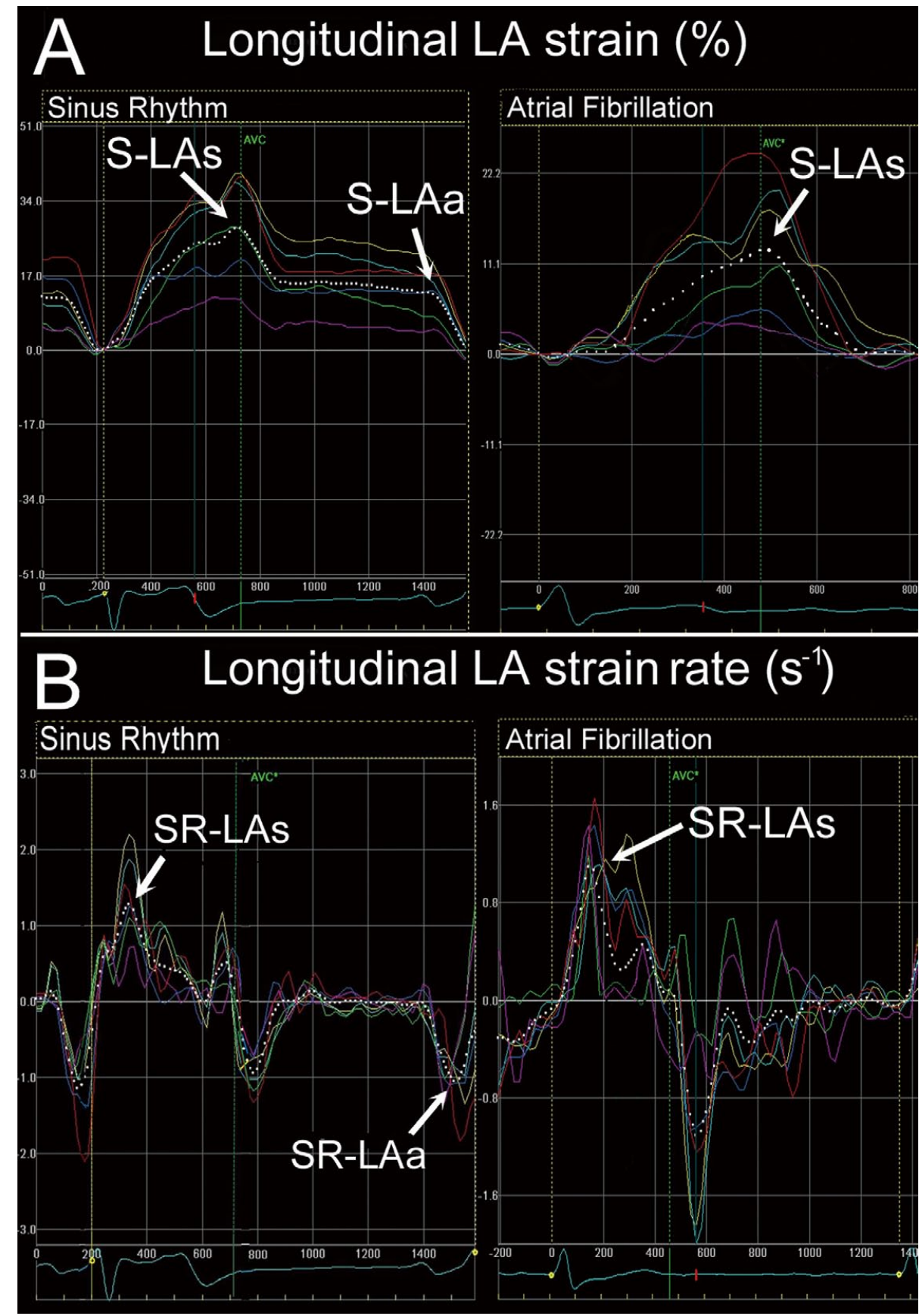

Figure 1. (A) Longitudinal strain and (B) strain rate of the 6 individually colored left atrium (LA) segments and the mean for all segments (dotted line). Each curve was obtained from patients with (Left) sinus rhythm and (Right) atrial fibrillation. S-LAs, peak LA strain at systole; SR-LAs, peak LA strain rate at ventricular systole. S-LAa and SR-LAa refer to these same measurements at ventricular late diastole. S-LAa and SR-LAa were not recorded during atrial fibrillation because of the lack of active contraction of LA. S-LAs, average of peak LA strain at systole; and global SR-LAs, average of peak LA strain rate at systole.

symptomatic drug-resistant persistent AF were candidates for CA at University of Tsukuba Hospital. Eighty-seven patients were excluded because of previous history of AF ablation $(n=46)$, impaired LVEF $(<50 \% ; n=12)$, significant heart valve disease (moderate or severe left-sided valvular stenosis and/or regurgitation, $n=7$ ), inadequate echocardiographic images $(n=10)$, or lack of follow-up data $(n=12)$. Finally, this study consisted of 123 patients with persistent AF. They included 80 patients with long-standing persistent $\mathrm{AF}$ (defined as continuous $\mathrm{AF}>1$ year). Of the subject group, 44 underwent combined therapy with class III and I anti-arrhythmic drugs (AADs) before CA. ${ }^{10}$ As a result, AF converted to SR in 27 patients before $\mathrm{CA}$, and $\mathrm{AF}$ continued in the remaining 96 patients until CA. Transesophageal echocardiography (TEE) was done twice 

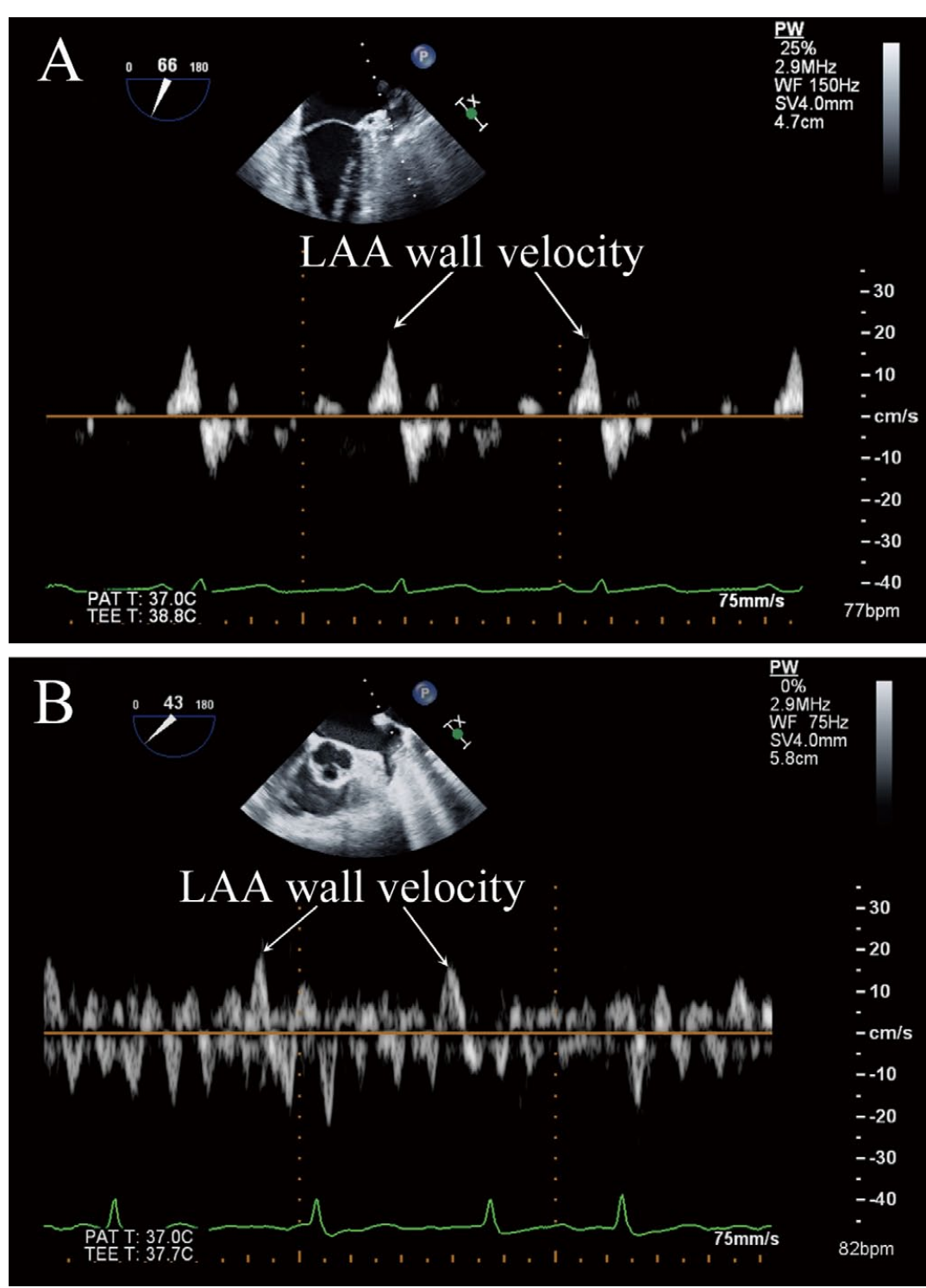

Figure 2. Measurements of Doppler tissue velocities of the left atrial appendage (LAA) wall performed during (A) sinus rhythm or (B) atrial fibrillation. (just before and 12 months after $\mathrm{CA}$ ) in all patients to exclude the presence of thrombus and evaluate LAA function. Transthoracic echocardiography (TTE) was performed 3 times (just before, just after, and 12 months after CA) to measure conventional parameters and LA strain/strain rate. Patients without AF recurrence were further divided into 2 subgroups according to whether follow-up indicated LA reverse remodeling. Ethics approval of the present study was obtained from the local review committee, and all patients provided written informed consent.

\section{TTE}

Two-dimensional (2-D) images were recorded with a Vivid 9 cardiovascular ultrasound system (GE Healthcare, Horten, Norway) with a combined 5.0-2.2-MHz Doppler transducer. The LA volume (LAV) was measured from the apical view with the biplane method of disks and was indexed to body surface area. Maximum LAV (LAVmax) was defined as the largest LAV just before mitral valve opening; minimum LAV (LAVmin) was defined as the smallest LAV in ventricular end- diastole. LA total emptying fraction (LAEF) was calculated by the following formula: ([LAVmax-LAVmin]/LAVmax) $\times 100$. The subjects was divided into 2 groups as follows: patients with reduction in LAVmax of $\geq 15 \%$ (responders), and patients who had either a reduction in LAVmax $<15 \%$ or an increase in volume at follow-up (non-responders), as previously described. ${ }^{11,12}$ LVEF was calculated using the Teichholz method. The peak velocities of early (E) and late (A) transmitral flow were recorded from the apical long-axis view on pulsed Doppler echocardiography. Tissue Doppler imaging was used to measure the early peak diastolic velocity (E') at the mitral annular septal and lateral corners. The E/E' ratio was calculated as $\mathrm{E}$ divided by the mean of the $2 \mathrm{E}$ ' velocities.

\section{LA Strain Analysis}

Longitudinal LA myocardial strain and strain rate were measured on 2-D speckle tracking echocardiography (2DSTE) according to a method slightly modified from a previous report. ${ }^{13}$ Grayscale images of apical views were obtained with frame rates of $50-80 \mathrm{~Hz}$. Recordings were processed with 


\begin{tabular}{|c|c|c|c|c|}
\hline & \multirow{2}{*}{$\begin{array}{c}\text { Total } \\
(n=123)\end{array}$} & \multicolumn{2}{|c|}{ Without AF recurrence $(n=78)$} & \multirow{2}{*}{$\begin{array}{l}\text { With AF } \\
\text { recurrence } \\
(n=45)\end{array}$} \\
\hline & & $\begin{array}{c}\text { Responders } \\
(\mathrm{n}=62)\end{array}$ & $\begin{array}{c}\text { Non-responders } \\
(n=16)\end{array}$ & \\
\hline Age (years) & $60 \pm 9$ & $60 \pm 9$ & $63 \pm 10$ & $60 \pm 9$ \\
\hline Male & $104(85)$ & $53(85)$ & $13(81)$ & $38(84)$ \\
\hline Body mass index $\left(\mathrm{kg} / \mathrm{m}^{2}\right)$ & $24.9 \pm 3.3$ & $24.7 \pm 3.3$ & $26.1 \pm 2.6$ & $24.8 \pm 3.7$ \\
\hline \multicolumn{5}{|l|}{ Heart rate (beats/min) } \\
\hline Just before CA & $72 \pm 22$ & $72 \pm 25$ & $73 \pm 21$ & $71 \pm 20$ \\
\hline Within $24 \mathrm{~h}$ after $\mathrm{CA}$ & $69 \pm 19$ & $69 \pm 19$ & $69 \pm 18$ & $69 \pm 19$ \\
\hline Twelve months after CA & $69 \pm 16$ & $68 \pm 15$ & $69 \pm 17$ & - \\
\hline Duration of AF (years) & $5.2 \pm 4.3$ & $4.5 \pm 4.5^{*}$ & $7.6 \pm 5.7$ & $5.4 \pm 3.0$ \\
\hline Long-standing persistent $\mathrm{AF}$ (continuous $\mathrm{AF}>1$ year) & $80(65)$ & $35(60)^{*}$ & $13(81)$ & $32(71)$ \\
\hline Hypertension & $69(56)$ & $30(48)$ & $9(56)$ & $30(67)$ \\
\hline Diabetes mellitus & $8(7)$ & $4(6)$ & $2(12)$ & $2(4)$ \\
\hline Coronary artery disease & $7(6)$ & $3(5)$ & $1(6)$ & $3(7)$ \\
\hline \multicolumn{5}{|l|}{ AADs before CA } \\
\hline Class I & $77(62)$ & $39(63)$ & $8(50)$ & $30(66)$ \\
\hline Class III & $90(73)$ & $43(69)$ & $13(81)$ & $34(76)$ \\
\hline Extensive AAD therapy (Class I+ III) & $44(36)$ & $20(32)$ & $5(31)$ & $19(42)$ \\
\hline Restoration of sinus rhythm before CA & $27(22)$ & $16(26)$ & $4(25)$ & $7(16)$ \\
\hline
\end{tabular}

Data given as mean $\pm \mathrm{SD}$ or $\mathrm{n}(\%)$. ${ }^{*} \mathrm{P}<0.05$ vs. non-responders. $\mathrm{AAD}$, anti-arrhythmic drug; $\mathrm{AF}$, atrial fibrillation; $\mathrm{CA}$, catheter ablation.

acoustic-tracking software (EchoPAC PC version 110.0.0, GE Healthcare) allowing off-line semi-automated speckle-based strain and strain rate analysis (Figure 1). The peak LA strain and strain rate during ventricular systole (S-LAs, SR-LAs, respectively) and at late diastole (S-LAa, SR-LAa, respectively) were calculated by taking the mean for all 12 segments, derived from the 6 segments of the 2-chamber and 4-chamber views. They were defined as global S-LAs, SR-LAs, S-LAa, SR-LAa, respectively. All measurements of heart structure and performance were averaged over 3 cardiac cycles during SR. In AF rhythm, an index beat, which is the beat after the nearly equal preceding (RR1) and pre-preceding (RR2) intervals, was used for each measurement as previously described. ${ }^{14,15}$

\section{TEE}

TEE was performed with commercially available ultrasound systems equipped with an X7-2t TEE transducer (Philips iE33; Philips Medical Systems, Andover, MA, USA). After the longitudinal view of the LAA was obtained, the highest emptying blood flow velocity was measured with pulsed Doppler, with the sample volume placed in proximity to the LAA orifice. To obtain tissue Doppler imaging of the LAA wall, the spectral Doppler signal filters were adjusted to obtain Nyquist limits of $20-30 \mathrm{~cm} / \mathrm{s}$ using the lowest wall filter settings and the minimum optimal gain in the same view. The sample volume $(4 \mathrm{~mm})$ was placed at the proximal third of the medial and at the lateral sidewalls of the LAA. ${ }^{16}$ LAA wall velocity was defined as the average of the peak upward velocity just before the QRS complex obtained from both the medial and lateral sidewalls of the LAA (Figure 2). LAA flow velocity and LAA wall velocity reflected active contraction of the LAA during SR or AF. ${ }^{17}$ Three consecutive beats in SR and 5 consecutive beats in AF were averaged to obtain these measurements. Spontaneous echo contrast (SEC) was identified as a dynamic smokelike signal that swirled slowly in a circular pattern in the LA and LAA. ${ }^{18}$ The acquired images were analyzed by 2 cardiologists blinded to any clinical information.

\section{CA and Post-Procedure Follow-up}

All AADs were discontinued for 5 half-lives before the procedure, with the exception of amiodarone, which was discontinued for at least 6 weeks beforehand. Extensive encircling pulmonary vein isolation (PVI) was performed using a doublelasso technique. ${ }^{19,20}$ After selective pulmonary vein (PV) angiography, 2 7-Fr decapolar ring catheters (Lasso, Biosense Webster, Diamond Bar, CA, USA) were positioned at each PV ostium. A 7.5-Fr irrigation catheter with a $3.5-\mathrm{mm}$ distal electrode (ThermoCool, Biosense Webster) was used for ablation. The endpoint of the extensive PVI was creation of extensive ipsilateral bidirectional conduction block from the atrium to the PVs and vice versa and confirmation of bidirectional conduction block at least $60 \mathrm{~min}$ after successful PVI. If AF was sustained after PVI, additional ablation consisting of linear ablation of the LA roof, superior vena cava isolation, and/or ablation of continuous fractionated atrial electrograms was performed. If $\mathrm{AF}$ did not terminate after that additional ablation, SR was restored by transthoracic cardioversion. ${ }^{19,20}$ A cavotricuspid isthmus block line was also created in all patients with confirmation of bidirectional block.

The patients remained hospitalized under continuous rhythm monitoring for approximately 5 days after the procedure. After discharge, the patients were followed at 2 weeks after the CA, and then every $1-3$ months at the outpatient clinic. ${ }^{19,20}$ At each hospital visit, the patients underwent a 12-lead electrocardiogram (ECG) and questioning regarding any arrhythmia-related symptoms. Twenty-four-hour Holter and portable ECG (HCG$901^{\circledR}$; OMRON, Kyoto, Japan) were performed at 2 weeks and $1,3,6$, and 12 months after CA. These tests were also done any time the patients reported palpitations. If the ECG showed any episodes of AF or any other atrial tachyarrhythmias lasting $>30$ s during follow-up, recurrence of AF was diagnosed. Recurrence of AF only within the first 3 months following the ablation was considered transient, however, and a blanking period of 3 months was applied. Patients with AF recurrence were treated temporarily with AADs, and discontinuation of the AADs was then attempted in those patients in whom the 


\begin{tabular}{|c|c|c|c|c|}
\hline & \multirow{2}{*}{$\begin{array}{c}\text { Total } \\
(n=123)\end{array}$} & \multicolumn{2}{|c|}{ Without AF recurrence $(n=78)$} & \multirow{2}{*}{$\begin{array}{l}\text { With AF } \\
\text { recurrence } \\
(n=45)\end{array}$} \\
\hline & & $\begin{array}{c}\text { Responders } \\
(n=62)\end{array}$ & $\begin{array}{c}\text { Non-responders } \\
(n=16)\end{array}$ & \\
\hline Total procedure time (min) & $341 \pm 61$ & $338 \pm 60$ & $327 \pm 56$ & $345 \pm 70$ \\
\hline Duration of RF energy (min) & $64 \pm 32$ & $62 \pm 37$ & $63 \pm 23$ & $66 \pm 33$ \\
\hline Total RF energy delivered $\left(\times 10^{3} \mathrm{~J}\right)$ & $107 \pm 58$ & $95 \pm 57$ & $124 \pm 95$ & $111 \pm 49$ \\
\hline \multicolumn{5}{|l|}{ Prevalence of additional ablation } \\
\hline Roof line & $101(82)$ & $54(87)$ & $12(75)$ & $35(77)$ \\
\hline Superior vena cava isolation & $46(37)$ & $21(34)$ & $7(43)$ & $18(40)$ \\
\hline Complex fractionated atrial electrogram ablation & $58(47)$ & $29(47)$ & $9(56)$ & $20(44)$ \\
\hline Cardioversion required at end of ablation & $25(20)$ & $13(21)$ & $3(19)$ & $9(20)$ \\
\hline
\end{tabular}

Data given as mean \pm SD or $n(\%)$. RF, radiofrequency. Other abbreviations as in Table 1 .

recurrent AF disappeared after temporary treatment; if SR could be maintained, the drugs were stopped permanently. Repeat ablation was not performed in any of the patients during the study period. All patients continued oral anticoagulation to maintain an international normalized ratio between 2.0 and 3.0 during the follow-up period.

\section{Statistical Analysis}

Results of 2DSTE are described using median and interquartile range because of skewed distribution, and other results are expressed as mean \pm SD or percentiles. One-way analysis of variance and post-hoc test were used to compare variables among 3 groups. Continuous variables between 2 groups were compared using paired t-test, unpaired t-test and Mann-Whitney U test as appropriate. Chi-square test, Fisher's exact probability test, and Wilcoxon signed-rank test were used for comparison of categorical variables, as appropriate. Logistic regression models were used to evaluate the univariate and multivariate influence of the explanatory variables on outcomes of CA. Echocardiographic parameters obtained just before procedures were used for analysis. S-LAa and SR-LAa were excluded from the analyses because baseline data were not obtained from every patient. Multivariate analysis was performed with variables that were statistically significant in univariate analysis, and which might have an effect on AF recurrence on the basis of previous studies. ${ }^{13,20,21}$ Those included the duration of AF, LAVmax, LAEF, global S-LAs, global SR-LAs, LAA flow velocity, and LAA wall velocity. The area under the receiver operating characteristic (ROC) curve was used to describe the prognostic value of the global S-LAs and LAA wall velocity for predicting maintenance of SR and LA reverse remodeling after CA. The duration of AF and LAV have been reported as important determinants for these outcomes; $; 1,13$ therefore, the predictive accuracy of these variables was compared to that of S-LAs and LAA wall velocity. Reproducibility of 2DSTE was tested in 20 randomly selected patients. $\mathrm{P}<0.05$ was considered to be statistically significant. All statistical analysis was performed using SPSS (version 16.0, SPSS, Chicago, IL, USA).

\section{Results}

\section{Subjects}

The general subject characteristics are summarized in Table $\mathbf{1 .}$ CA was successfully performed in all patients, with no major complications (eg, stroke, atrio-esophageal fistula). The mean follow-up period was 18.0 \pm 2.3 months (range, 16-20 months), with 45 patients $(37 \%)$ experiencing $\mathrm{AF}$ recurrence during this period. Of the 78 patients (63\%) without recurrent AF, $62(79 \%)$ were classified as responders, whereas $16(21 \%)$ were nonresponders. Although the duration of AF was shorter and prevalence of long-standing persistent $\mathrm{AF}$ was lower in responders than in non-responders, no statistically significant differences were found in other clinical parameters among the 3 groups.

\section{Ablation}

Results and data from CA are listed in Table 2. The duration of the procedure, duration of the radiofrequency application, delivered radiofrequency energy, and the prevalence of additional ablation were similar among the 3 groups.

\section{Echocardiography}

Parameter changes of LA and LAA function are illustrated in Figure 3. The other echocardiographic findings are compared in Table 3. LA strain, strain rate, LAA flow velocity, and LAA wall velocity at baseline were greater in responders compared to other 2 groups, but there was no significant difference between non-responders and patients with AF recurrence. In responders, both LAVmax and LAVmin significantly decreased at 12 months after CA compared with baselines. Moreover, LA strain, strain rate and LAEF in responders improved in the follow-up period in contrast to those in non-responders, who had no change in these parameters. Responders had a lower prevalence of SEC at baseline compared with non-responders and patients with AF recurrence. The prevalence of SEC after maintaining SR for 12 months was reduced from $26 \%$ to $3 \%$ in the responders, but it did not significantly change in nonresponders and patients with $\mathrm{AF}$ recurrence. Thrombus in the LAA was not present in any patient at follow-up. Although LVEF at baseline was similar among the groups, it was improved only in responders at the end of the study.

\section{Prediction of Maintenance of SR and LA Reverse Remodeling}

Results of the logistic regression analysis for maintenance of SR and LA reverse remodeling are summarized in Table 4. Multivariate analysis identified global S-LAs and LAA wall velocity as independent predictors of maintenance of SR (odds ratio, [OR] 2.57; $\mathrm{P}=0.003 ; \mathrm{OR}, 3.02 ; \mathrm{P}=0.002$, respectively) and also of LA reverse remodeling $(\mathrm{OR}, 4.44 ; \mathrm{P}=0.007$; $\mathrm{OR}$, 3.52; $\mathrm{P}=0.01$, respectively) after $\mathrm{CA}$.

According to the ROC curve analysis, global S-LAs and LAA wall velocity were more accurate in predicting both maintenance of SR (Figure 4A) and LA reverse remodeling (Figure 4B) than were the LAV index and AF duration. 

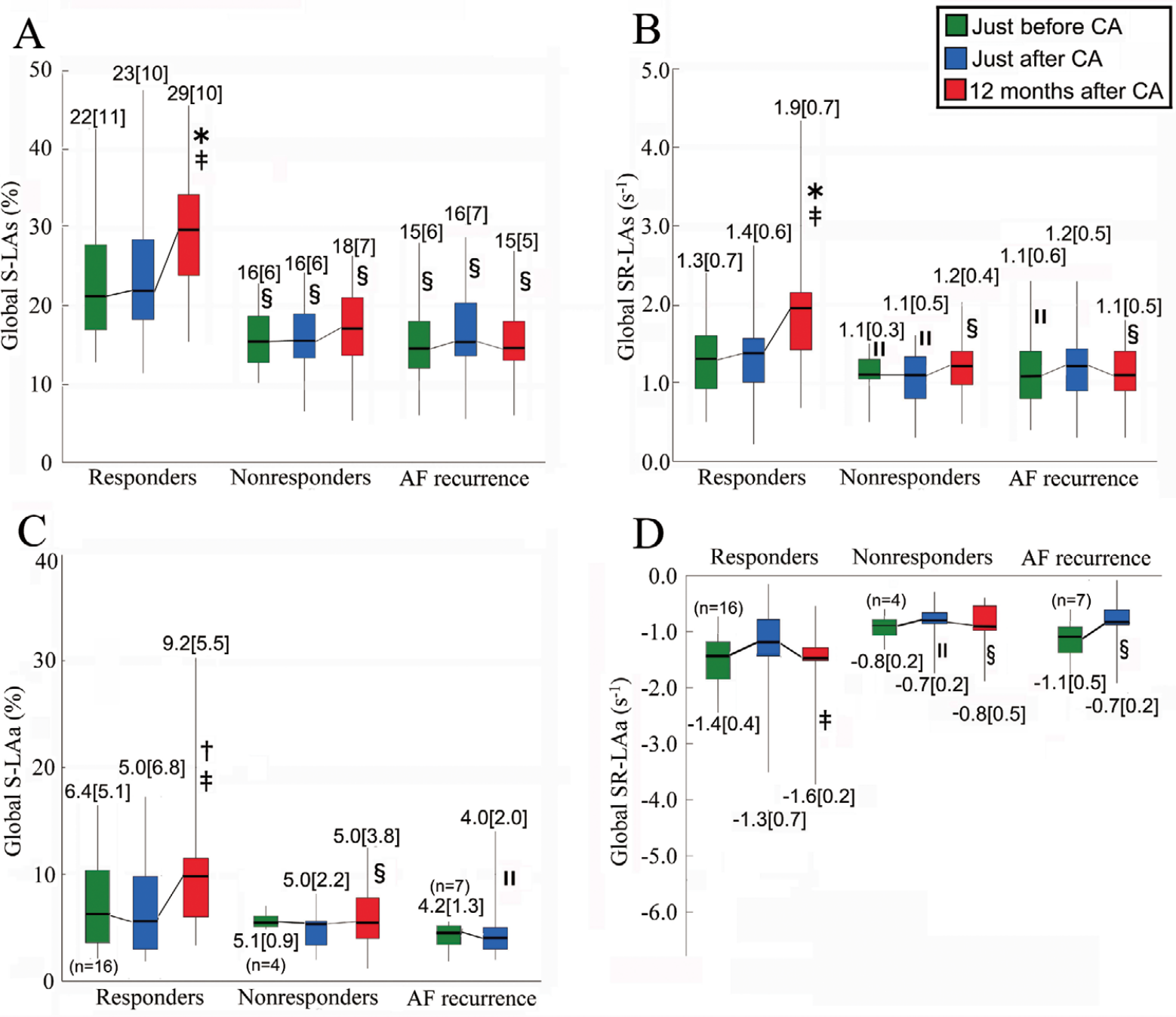

$\mathrm{E}$

$\mathrm{F}$
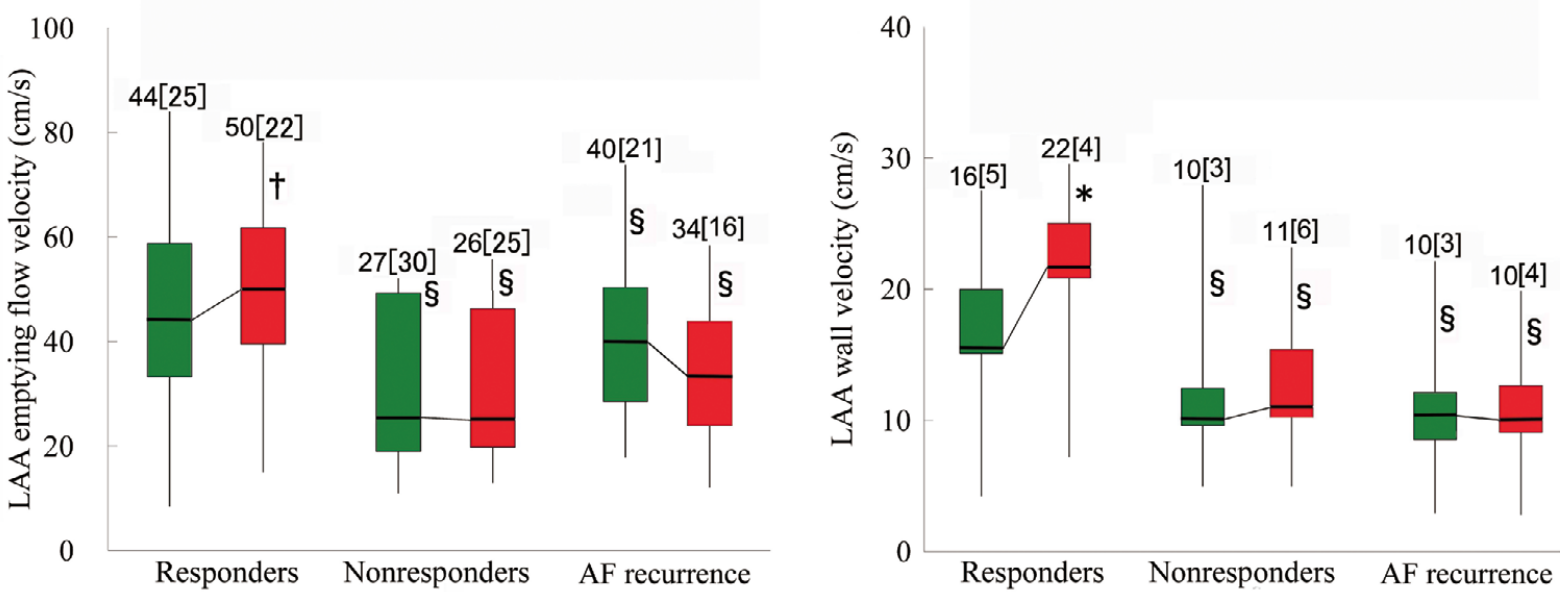

Figure 3. (A) Global S-LAs, (B) global SR-LAs, (C) global S-LAa, (D) global SR-LAa, (E) left atrial appendage (LAA) emptying flow velocity, and (F) LAA wall velocity at baseline and at 12 months after catheter ablation (CA). S-LAa and SR-LAa were not available in patients with atrial fibrillation (AF). Data given as median (interquartile range). Global S-LAs, mean of peak LA strain at systole; global SR-LAs, mean of peak LA strain rate at systole. Global S-LAa and global SR-LAa refer to these same measure-

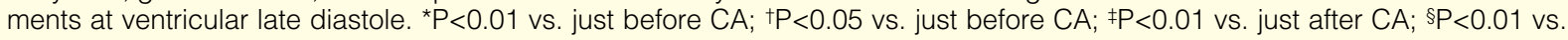
responders; $\| P<0.05$ vs. responders. 


\begin{tabular}{|c|c|c|c|}
\hline \multirow[b]{2}{*}{ Parameters } & \multicolumn{2}{|c|}{ Without AF recurrence $(n=78)$} & \multirow{2}{*}{$\begin{array}{c}\text { With AF } \\
\text { recurrence } \\
(n=45)\end{array}$} \\
\hline & $\begin{array}{l}\text { Responders } \\
(n=62)\end{array}$ & $\begin{array}{c}\text { Non-responders } \\
(n=16)\end{array}$ & \\
\hline \multicolumn{4}{|l|}{$\operatorname{LAVmax}\left(\mathrm{ml} / \mathrm{m}^{2}\right)$} \\
\hline Just before CA & $48 \pm 25$ & $56 \pm 22$ & $57 \pm 23$ \\
\hline Follow-up & $34 \pm 16^{*}$ & $56 \pm 25^{\dagger}$ & $59 \pm 22^{\dagger}$ \\
\hline \multicolumn{4}{|l|}{$\mathrm{LAVmin}\left(\mathrm{ml} / \mathrm{m}^{2}\right)$} \\
\hline Just before CA & $40 \pm 19$ & $48 \pm 22$ & $47 \pm 16^{\ddagger}$ \\
\hline Follow-up & $23 \pm 12^{*}$ & $44 \pm 18^{\dagger}$ & $49 \pm 20^{\star}, \dagger$ \\
\hline \multicolumn{4}{|l|}{ LAEF (\%) } \\
\hline Just before CA & $24 \pm 17$ & $25 \pm 16$ & $21 \pm 16$ \\
\hline Follow-up & $36 \pm 14^{*}$ & $24 \pm 11^{\dagger}$ & $17 \pm 14^{\star},+, \S$ \\
\hline \multicolumn{4}{|l|}{ SEC in LA or LAA } \\
\hline Just before CA & $16(26)$ & $11(69)^{\dagger}$ & $28(62)^{\ddagger}$ \\
\hline Follow-up & $2(3)^{*}$ & $9(56)^{\dagger}$ & $27(60)^{\dagger}$ \\
\hline \multicolumn{4}{|c|}{ Mitral peak E-wave velocity $(\mathrm{cm} / \mathrm{s})$} \\
\hline Just before CA & $76 \pm 20$ & $73 \pm 16$ & $76 \pm 18$ \\
\hline Follow-up & $68 \pm 17^{*}$ & $69 \pm 19$ & $78 \pm 24$ \\
\hline \multicolumn{4}{|l|}{ Mitral peak A-wave velocity $(\mathrm{cm} / \mathrm{s})$} \\
\hline Just before CA $(n=27)$ & $54 \pm 12(n=16)$ & $49 \pm 8(n=4)$ & $46 \pm 16(n=7)$ \\
\hline Follow-up & $63 \pm 19$ & $47 \pm 14^{\dagger}$ & - \\
\hline \multicolumn{4}{|l|}{ E/A ratio } \\
\hline Just before CA $(n=27)$ & $1.4 \pm 0.7(n=16)$ & $1.5 \pm 0.4(n=4)$ & $1.6 \pm 0.7(n=7)$ \\
\hline Follow-up & $1.1 \pm 0.4$ & $1.6 \pm 0.7^{\ddagger}$ & - \\
\hline \multicolumn{4}{|l|}{ E/E' ratio } \\
\hline Just before CA & $8.4 \pm 4.7$ & $9.1 \pm 2.9$ & $8.9 \pm 3.4$ \\
\hline Follow-up & $8.1 \pm 3.3$ & $9.2 \pm 1.8$ & $8.9 \pm 3.2$ \\
\hline \multicolumn{4}{|l|}{ LV ejection fraction (\%) } \\
\hline Just before CA & $63 \pm 11$ & $64 \pm 11$ & $64 \pm 9$ \\
\hline Follow-up & $69 \pm 6^{*}$ & $66 \pm 11$ & $65 \pm 78$ \\
\hline
\end{tabular}

Data given as mean $\pm S D$ or $n(\%)$. ${ }^{*}<<0.01$ vs. baseline; $t P<0.01$ vs. responders; $\$ P<0.05$ vs. responders; $\$ P<0.05$ vs. non-responders. LA, left atrial/left atrium; LAA, LA appendage; LAEF, LA total emptying fraction; LAVmax, maximum LA volume; LAVmin, minimum LA volume; LV, left ventricular; SEC, spontaneous echo contrast. Other abbreviations as in Table 1.

Table 4. Predictors of Outcome of AF Ablation

Outcomes

Age (years)

Duration of AF (years)

$\operatorname{LAVmax}\left(\mathrm{ml} / \mathrm{m}^{2}\right)$

$\operatorname{LAEF}(\%)$

Global S-LAs ${ }^{\dagger}$

Global SR-LAs

LAA flow velocity ${ }^{\dagger}$

LAA wall velocity ${ }^{\dagger}$

\section{Maintenance of sinus rhythm}

\begin{tabular}{|c|c|c|c|}
\hline \multicolumn{2}{|c|}{ Univariate } & \multicolumn{2}{|c|}{ Multivariate } \\
\hline OR $(95 \% \mathrm{Cl})$ & $\mathrm{P}$-value & OR $(95 \% \mathrm{Cl})$ & P-value \\
\hline $\begin{array}{c}1.01 \\
(0.97-1.06)\end{array}$ & 0.51 & & \\
\hline
\end{tabular}

$$
0.97
$$$$
\text { (0.89-1.06) }
$$$$
0.98
$$$$
(0.97-1.001)
$$

$$
1.03
$$$$
(1.00-1.06)
$$

$$
3.65
$$$$
(2.04-6.54)
$$$$
1.43
$$$$
\text { (0.97-2.10) }
$$

$$
2.06
$$$$
\text { (1.28-3.32) }
$$

(2.26-8.30)
0.07

0.06

$<0.001$

0.07

0.003

$<0.001$

\begin{tabular}{|c|c|c|c|}
\hline \multicolumn{2}{|c|}{ Univariate } & \multicolumn{2}{|c|}{ Multivariate } \\
\hline OR (95\% Cl) & P-value & OR $(95 \% \mathrm{Cl})$ & P-value \\
\hline $\begin{array}{c}0.97 \\
(0.91-1.03)\end{array}$ & 0.29 & & \\
\hline $\begin{array}{c}0.87 \\
(0.77-0.98)\end{array}$ & 0.01 & $\begin{array}{c}0.91 \\
(0.79-1.05)\end{array}$ & 0.19 \\
\hline $\begin{array}{c}0.99 \\
(0.96-1.01)\end{array}$ & 0.21 & & \\
\hline $\begin{array}{c}1.04 \\
(1.01-1.09)\end{array}$ & 0.048 & $\begin{array}{c}0.97 \\
(0.91-1.04)\end{array}$ & 0.42 \\
\hline $\begin{array}{c}6.03 \\
(2.06-17.64)\end{array}$ & 0.001 & $\begin{array}{c}4.44 \\
(1.51-13.03)\end{array}$ & 0.007 \\
\hline $\begin{array}{c}1.73 \\
(0.96-3.12)\end{array}$ & 0.07 & & \\
\hline $\begin{array}{c}2.92 \\
(1.37-6.22)\end{array}$ & 0.006 & & \\
\hline $\begin{array}{c}3.57 \\
(1.56-8.19)\end{array}$ & 0.003 & $\begin{array}{c}3.52 \\
(1.33-9.29)\end{array}$ & 0.01 \\
\hline
\end{tabular}

$$
\begin{gathered}
1.76 \\
(0.94-3.29) \\
3.02
\end{gathered}
$$$$
\text { (1.53-5.98) }
$$

\section{LA reverse remodeling}

${ }^{\dagger}$ Per 1-SD increase. Echocardiographic parameters obtained just before procedure were used for analysis. $\mathrm{Cl}$, confidence interval; global S-LAs, mean of peak LA strain at systole; global SR-LAs, mean of peak LA strain rate at systole; OR, odds ratio. Other abbreviations as in Tables 1,3. 


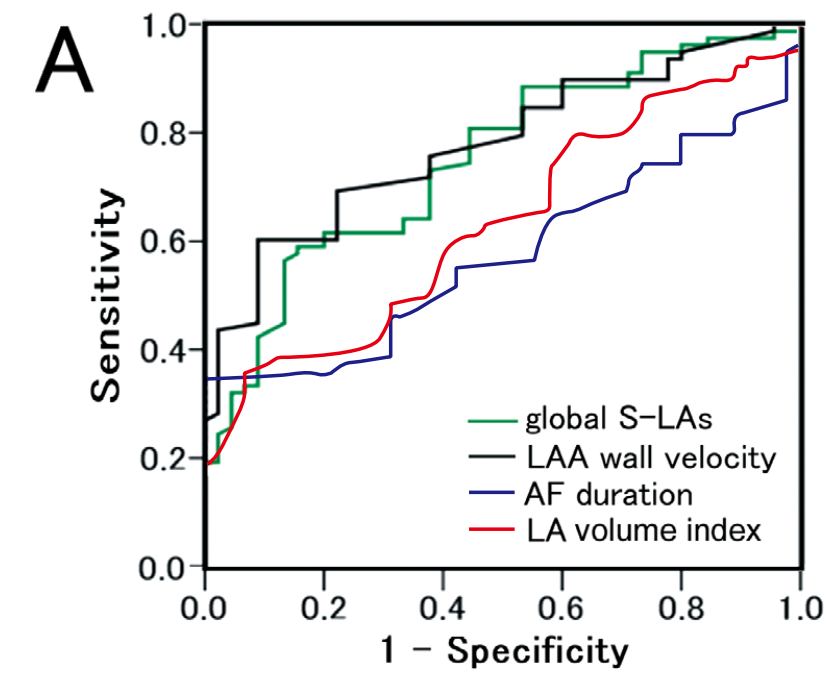

\begin{tabular}{lcccc}
\hline & AUC $(95 \% \mathrm{CI})$ & p-value & sensitivity & specificity \\
\hline - global S-LAs & $0.75(0.66-0.84)$ & $<0.001$ & $56 \%$ & $87 \%$ \\
- LAA wall velocity & $0.78(0.70-0.86)$ & $<0.001$ & $60 \%$ & $91 \%$ \\
- AF duration & $0.58(0.48-0.68)$ & 0.13 & $17 \%$ & $100 \%$ \\
- LA volume index & $0.63(0.54-0.71)$ & 0.02 & $36 \%$ & $93 \%$ \\
\hline
\end{tabular}

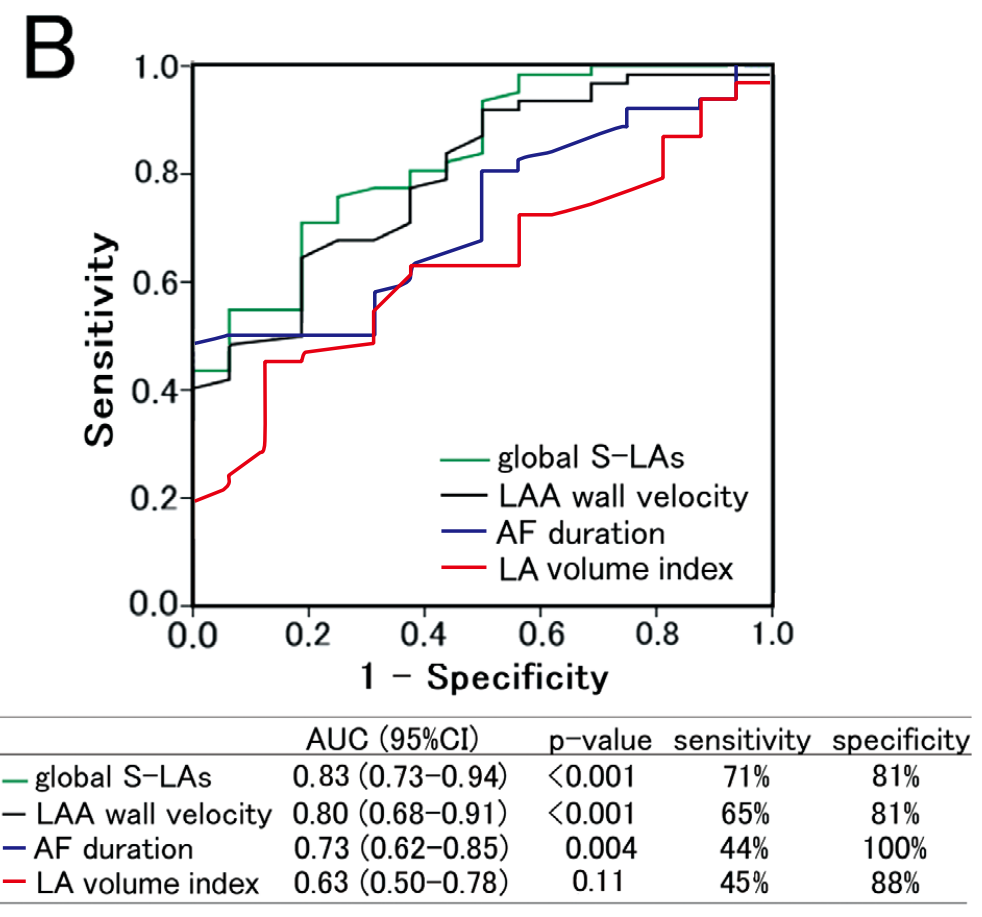

Figure 4. Prediction of maintenance of (A) sinus rhythm and (B) left atrium (LA) reverse remodeling after catheter ablation. Green line, mean of peak LA strain at systole (global S-LAs); black line, LA appendage (LAA) wall velocity; blue line, atrial fibrillation (AF) duration; red line, LA volume index. Cut-off points of each variables in (A) are $20.1 \%$, $12.1 \mathrm{~cm} / \mathrm{s}, 1.3$ years, and $37.3 \mathrm{ml} / \mathrm{m}^{2}$. Cut-off points in (B) are $18.4 \%, 13.1 \mathrm{~cm} / \mathrm{s}, 2.4$ years, and $41.7 \mathrm{ml} / \mathrm{m}^{2}$.

\section{Reproducibility}

Intraobserver correlation coefficients and mean absolute percentage errors for S-LAs, SR-LAs, S-LAa and SR-LAa were 0.98 and $6.7 \pm 4.9 \%, 0.92$ and $11.3 \pm 8.7 \%, 0.95$ and $10.0 \pm 4.9 \%$, and 0.97 and $8.7 \pm 5.0 \%$, respectively. Interobserver correlation coefficients and mean absolute percentage errors for the same parameters were 0.89 and $9.3 \pm 7.2 \%, 0.74$ and $12.0 \pm 7.7 \%, 0.88$ and $13.2 \pm 10.6 \%$, and 0.89 and $11.5 \pm 8.2 \%$, respectively.

\section{Discussion}

\section{Major Findings}

This study has shown that: (1) LA reverse remodeling after CA is associated with significantly greater global S-LAs and LAA wall velocity at baseline, which are independent predictors of both maintenance of SR and LA reverse remodeling; (2) LA reverse remodeling is associated with recovered LA/ LAA functions at 12-month follow-up; and (3) the absence of 
LA reverse remodeling is associated with impaired LA/LAA function and a higher prevalence of SEC at follow-up, even in SR.

\section{LA Reverse Remodeling and Improvement of LA/LAA Function After AF Ablation}

Although LA remodeling progresses in persistent $A F,{ }^{1-3}$ in the present study the majority of the cohort experienced LA reverse remodeling after successful CA. The mechanism of LAV reduction after CA remains controversial but several studies have shown sustained LA dysfunction after ablation and inferred that ablation causes atrial scarring and loss of atrial myocardial mass, which prevents further LA dilatation. ${ }^{22,23} \mathrm{In}$ the present study, ablation procedures did not differ between responders and non-responders. Moreover, the LAV reduction occurring in responders was accompanied by amelioration of LA function. This suggests that even if CA produces partial scarring in the LA, it is overridden by the benefit of maintenance of SR, which brings histological reverse remodeling and functional LA recovery. Also in LAA, responders had improvements of functional parameters after CA. Moreover, all but 2 responders had diminished SEC at follow-up. Non-responders, however, had no significant improvement of LA/LAA functions after CA, and more than half of them had SEC despite the maintenance of SR. SEC is a well-established risk factor of thrombus formation and embolic events, ${ }^{18}$ therefore it is a notable finding.

The degree of denaturation of the LA/LAA has been correlated with the duration of AF. ${ }^{1-3}$ In the current study nonresponders had a longer AF duration and LA/LAA dysfunction at baseline, similar to the previous study. ${ }^{24}$ This indicates that it may be more difficult to recover atrial condition in nonresponders due to the greater deterioration of atrial histological alteration, but further investigation is needed.

\section{Predictors for Maintenance of SR and LA Reverse Remodeling}

In this study, we identified S-LAs and LAA wall velocity at baseline as independent predictors of both maintenance of SR and LA reverse remodeling after $\mathrm{CA}$ for persistent AF. The predictive accuracy of S-LAs and LAA wall velocity was better than that of conventional predictors such as LAV and duration of AF. This may be because 2-D echocardiography tends to underestimate LAV, especially in enlarged LA, ${ }^{25}$ and duration of AF may be subjective and sometimes less reliable because it is mainly estimated by patient interviews.

Although multiple non-invasive techniques have been proposed to assess atrial function, a gold-standard technique is still lacking. The present study has shown, however, that S-LAs reflects atrial condition despite its measurement during AF. S-LAs is inversely related to atrial fibrosis and stiffness, and several reports have indicated its usefulness as a marker of LA remodeling. ${ }^{13,26}$ As regards other parameters, transmitral flow and PV flow velocities are highly dependent on loading conditions and LV diastolic function. As shown in the present study and another report, LAEF is inferior to myocardial-deformation imaging techniques in detecting subtle changes in LA function. ${ }^{11}$ LA strain rate did not have significant predictive power of maintenance of SR and LA reverse remodeling in the present study because of its low reproducibility, as was also found in a previous study ${ }^{27}$ Taking these findings into account, S-LAs can be used as a highly reproducible and reliable parameter of atrial condition for patients with AF.

LAA wall velocity can indicate LAA function and is useful for risk stratification of LAA thrombus formation and cardio- embolic stroke, ${ }^{9}$ but we believe that this is the first report to identify an association between LAA wall velocity and LA reverse remodeling or maintenance of SR after AF ablation. Although persistent AF causes myocytolysis and interstitial fibrosis in the LAA as well as the LA main chamber, the degree of these conditions is often mild in the LAA compared with the LA. ${ }^{28}$ Because there are embryologic and structural differences between the LAA and LA main chamber, LAA function does not always parallel LA function..$^{29}$ Nevertheless, LAA wall velocity had predictive power of favorable outcome after CA in the present patients, who mainly had long-standing persistent AF. This suggests that long duration of AF may result in histological degeneration of the LAA that progresses to the same extent as that of the LA main chamber. Evaluation of LAA wall velocity on TEE is not time-consuming and every patient undergoes TEE before AF ablation. Therefore, we believe that LAA wall velocity is worth evaluating for the prediction of favorable outcome of CA.

\section{Clinical Implications}

Importantly, S-LAs and LAA wall velocity were useful in prediction of both maintenance of SR and LA reverse remodeling after $\mathrm{AF}$ ablation, and these findings may provide a new viewpoint for indication of CA. Despite the restoration of SR and continuation of appropriate anticoagulation therapy, patients without LA reverse remodeling had LA/LAA dysfunction and a higher prevalence of SEC. This suggests an increased risk of thromboembolism even after elimination of the AF. Therefore, this study identifies some potentially important clinical issues regarding the follow-up and anticoagulation regimen in patients without LA reverse remodeling, despite the presence of SR.

\section{Study Limitations}

First, 24-h Holter monitoring is less effective for the detection of asymptomatic recurrence of atrial arrhythmias, compared with trans-telephonic daily monitoring or implantable loop recorders. ${ }^{30}$ The follow-up strategy after CA in the present study, however, was in line with the methodology of previous studies investigating LA reverse remodeling after AF ablation., Second, some patients were restored to SR by extensive AAD therapy before ablation procedures and others had continued AF until CA. Thus, difference in cardiac rhythm might have influenced the baseline echocardiographic results. Measurements from the index beat or multiple cardiac cycles that we used, however, have been recognized as an accurate method to assess cardiac function, even in AF..$^{14,15}$ Moreover, the proportion of patients with SR before CA did not significantly differ among the groups. Consequently, we consider that these limitations did not affect the main results, but further studies are mandatory to confirm these results.

\section{Conclusions}

The majority of patients with persistent AF experienced LA reverse remodeling and long-term maintenance of SR after successful CA. Greater LA systolic strain and LAA wall velocity at baseline were related to maintenance of SR, LA reverse remodeling and amelioration of LA/LAA functions after CA.

\section{Disclosures}

None. 


\section{References}

1. Gramley F, Lorenzen J, Plisiene J, Rakauskas M, Benetis R, Schmid $\mathrm{M}$, et al. Decreased plasminogen activator inhibitor and tissue metalloproteinase inhibitor expression may promote increased metalloproteinase activity with increasing duration of human atrial fibrillation. J Cardiovasc Electrophysiol 2007; 18: 1076-1082.

2. Thijssen VL, Ausma J, Liu GS, Allessie MA, van Eys GJ, Borgers M. Structural changes of atrial myocardium during chronic atrial fibrillation. Cardiovasc Pathol 2000; 9: 17-28.

3. Xu J, Cui G, Esmailian F, Plunkett M, Marelli D, Ardehali A, et al. Atrial extracellular matrix remodeling and the maintenance of atrial fibrillation. Circulation 2004; 109: 363-368.

4. Chang SH, Tsao HM, Wu MH, Tai CT, Chang SL, Wongcharoen W, et al. Morphological changes of the left atrial appendage after catheter ablation of atrial fibrillation. J Cardiovasc Electrophysiol 2007; 18: $47-52$.

5. Lévy S, Maarek M, Coumel P, Guize L, Lekieffre J, Medvedowsky $\mathrm{JL}$, et al. Characterization of different subsets of atrial fibrillation in general practice in France: The ALFA study: The College of French Cardiologists. Circulation 1999; 99: 3028-3035.

6. Reant P, Lafitte S, Jaïs P, Serri K, Weerasooriya R, Hocini M, et al. Reverse remodeling of the left cardiac chambers after catheter ablation after 1 year in a series of patients with isolated atrial fibrillation. Circulation 2005; 112: 2896-2903.

7. Nieuwlaat R, Prins MH, Le Heuzey JY, Vardas PE, Aliot E, Santini M, et al. Prognosis, disease progression, and treatment of atrial fibrillation patients during 1 year: Follow-up of the Euro Heart Survey on atrial fibrillation. Eur Heart J 2008; 29: 1181 - 1189.

8. de Vos CB, Pisters R, Nieuwlaat R, Prins MH, Tieleman RG, Coelen $\mathrm{RJ}$, et al. Progression from paroxysmal to persistent atrial fibrillation: Clinical correlates and prognosis. J Am Coll Cardiol 2010; 55: $725-$ 731.

9. Uretsky S, Shah A, Bangalore S, Rosenberg L, Sarji R, Cantales DR, et al. Assessment of left atrial appendage function with transthoracic tissue doppler echocardiography. Eur J Echocardiogr 2009; 10: 363 371.

10. Igarashi M, Tada H, Sekiguchi Y, Yamasaki H, Arimoto T, Kuroki K, et al. Effect of restoration of sinus rhythm by extensive antiarrhythmic drugs in predicting results of catheter ablation of persistent atrial fibrillation. Am J Cardiol 2010; 106: 62-68.

11. Tops LF, Delgado V, Bertini M, Marsan NA, Den Uijl DW, Trines $\mathrm{SA}$, et al. Left atrial strain predicts reverse remodeling after catheter ablation for atrial fibrillation. J Am Coll Cardiol 2011; 57: 324-331.

12. Westenberg JJ, van der Geest RJ, Lamb HJ, Versteegh MI, Braun J, Doornbos J, et al. MRI to evaluate left atrial and ventricular reverse remodeling after restrictive mitral annuloplasty in dilated cardiomyopathy. Circulation 2005; 112 (9 Suppl): I437-I442.

13. Machino-Ohtsuka T, Seo Y, Tada H, Ishizu T, Machino T, Yamasaki $\mathrm{H}$, et al. Left atrial stiffness relates to left ventricular diastolic dysfunction and recurrence after pulmonary vein isolation for atrial fibrillation. J Cardiovasc Electrophysiol 2011; 22: 999-1006.

14. Kusunose K, Yamada H, Nishio S, Tomita N, Hotchi J, Bando M, et al. Index-beat assessment of left ventricular systolic and diastolic function during atrial fibrillation using myocardial strain and strain rate. J Am Soc Echocardiogr 2012; 25: 953-959.

15. Tabata T, Grimm RA, Greenberg NL, Agler DA, Mowrey KA, Wallick DW, et al. Assessment of LV systolic function in atrial fibrillation using an index of preceding cardiac cycles. Am J Physiol Heart Circ Physiol 2001; 281: H573-H580.

16. Parvathaneni L, Mahenthiran J, Jacob S, Foltz J, Gill WJ, Ghumman $\mathrm{W}$, et al. Comparison of tissue doppler dynamics to doppler flow in evaluating left atrial appendage function by transesophageal echo- cardiography. Am J Cardiol 2005; 95: 1011-1014.

17. Fatkin D, Feneley MP. Patterns of doppler-measured blood flow velocity in the normal and fibrillating human left atrial appendage. Am Heart J 1996; 132: 995-1003.

18. Chimowitz MI, DeGeorgia MA, Poole RM, Hepner A, Armstrong WM. Left atrial spontaneous echo contrast is highly associated with previous stroke in patients with atrial fibrillation or mitral stenosis. Stroke 1993; 24: 1015-1019.

19. Naruse Y, Tada H, Satoh M, Yanagihara M, Tsuneoka H, Hirata Y, et al. Radiofrequency catheter ablation of persistent atrial fibrillation decreases a sleep-disordered breathing parameter during a short follow-up period. Circ J 2012; 76: 2096-2103.

20. Machino T, Tada H, Sekiguchi Y, Yamasaki H, Kuroki K, Igarashi M, et al. Prevalence and influence of hyperthyroidism on the long-term outcome of catheter ablation for drug-refractory atrial fibrillation. Circ J 2012; 76: 2546-2551.

21. Schneider C, Malisius R, Krause K, Lampe F, Bahlmann E, Boczor S, et al. Strain rate imaging for functional quantification of the left atrium: Atrial deformation predicts the maintenance of sinus rhythm after catheter ablation of atrial fibrillation. Eur Heart J 2008; 29: 1397 1409.

22. Thomas L, Thomas SP, Hoy M, Boyd A, Schiller NB, Ross DL. Comparison of left atrial volume and function after linear ablation and after cardioversion for chronic atrial fibrillation. Am J Cardiol 2004; 93: 165-170.

23. Thomas SP, Nicholson IA, Nunn GR, Rees A, Trieu L, Daly MP, et al. Effect of atrial radiofrequency ablation designed to cure atrial fibrillation on atrial mechanical function. J Cardiovasc Electrophysiol 2000; 11: $77-82$.

24. Kuppahally SS, Akoum N, Badger TJ, Burgon NS, Haslam T, Kholmovski E, et al. Echocardiographic left atrial reverse remodeling after catheter ablation of atrial fibrillation is predicted by preablation delayed enhancement of left atrium by magnetic resonance imaging. Am Heart J 2010; 160: 877-884.

25. Miyasaka Y, Tsujimoto S, Maeba H, Yuasa F, Takehana K, Dote K, et al. Left atrial volume by real-time three-dimensional echocardiography: Validation by 64-slice multidetector computed tomography. $J$ Am Soc Echocardiogr 2011; 24: 680-686.

26. Kuppahally SS, Akoum N, Burgon NS, Badger TJ, Kholmovski EG, Vijayakumar S, et al. Left atrial strain and strain rate in patients with paroxysmal and persistent atrial fibrillation: Relationship to left atrial structural remodeling detected by delayed-enhancement MRI. Circ Cardiovasc Imaging 2010; 3: 231-239.

27. Di Salvo G, Caso P, Lo Piccolo R, Fusco A, Martiniello AR, Russo MG, et al. Atrial myocardial deformation properties predict maintenance of sinus rhythm after external cardioversion of recent-onset lone atrial fibrillation: A color Doppler myocardial imaging and transthoracic and transesophageal echocardiographic study. Circulation 2005; 112: 387-395.

28. Corradi D, Callegari S, Benussi S, Maestri R, Pastori P, Nascimbene $\mathrm{S}$, et al. Myocyte changes and their left atrial distribution in patients with chronic atrial fibrillation related to mitral valve disease. Hum Pathol 2005; 36: 1080-1089.

29. Agmon Y, Khandheria BK, Meissner I, Petterson TM, O'Fallon WM, Wiebers DO, et al. Are left atrial appendage flow velocities adequate surrogates of global left atrial function? A population-based transthoracic and transesophageal echocardiographic study. J Am Soc Echocardiogr 2002; 15: 433-440.

30. Arya A, Piorkowski C, Sommer P, Kottkamp H, Hindricks G. Clinical implications of various follow up strategies after catheter ablation of atrial fibrillation. Pacing Clin Electrophysiol 2007; 30: 458462. 